\title{
Monitoring Kualitas Air Secara Real-Time Terintegrasi
}

\author{
Integrated Real-time Water Quality Monitoring \\ Yudi Yuliyus Maulana*, Dadin Mahmudin, R. Indra Wijaya dan Goib Wiranto
}

Pusat Penelitian Elektronika dan Telekomunikasi, Lembaga Ilmu Pengetahuan Indonesia.
Komp LIPI Gd 20, Jl Sangkuriang 21/54D, Bandung 40135, Indonesia

\begin{abstract}
Abstrak
Perkembangan budi daya ikan yang menggunakan keramba jaring apung (KJA), saat ini tersebar di berbagai waduk dan danau di seluruh Indonesia, saat ini tumbuh pesat dan menjadi andalan pendapatan daerah. Selama ini monitoring kualitas air dilakukan secara manual, yaitu melakukan pengukuran kualitas air di tempat budidaya ikan tersebut. Selain memerlukan waktu yang lama, biasanya budi daya ikan tersebut berada jauh dari pusat kota. Dalam makalah ini akan dijelaskan desain dan realisasi sistem monitoring kualitas air dan peringatan dini secara real-time yang terintegrasi. Sistem ini telah diterapkan secara khusus untuk memantau parameter suhu, DO (dissolved oxygen) dan pH di sentral budidaya ikan di Waduk Cirata. Tujuannya adalah memantau kualitas air secara real-time, bisa diakses di mana saja dan sekaligus mencegah kematian ikan secara massal yang disebabkan oleh terjadinya up-welling dengan menggunakan sistem peringatan dini. upwelling terjadi apabila nilai suhu menurun drastis mencapai 25 derajat celcius lalu nilai DO menurun sampai $2,38 \mathrm{mg} / \mathrm{L}$. Di sisi lain, data dari stasiun pengukuran yang dikumpulkan di stasiun perantara dapat diakses atau dikirimkan ke stasiun pengendali dengan menggunakan sistem telemetri. Hasil dari penelitian ini memperlihatkan suatu sistem monitoring kualitas air untuk memantau parameter suhu, DO dan $\mathrm{pH}$ sekaligus peringatan dini terjadinya upwelling. Sistem ini untuk mendukung pembudidayaan ikan di danau-danau di Indonesia.
\end{abstract}

Kata kunci: budidaya ikan, kualitas air, peringatan dini, real-time, suhu, upwelling.

\section{Abstract}

Development of fish farming by means of keramba jaring apung (KJA) method, which is found in many lakes in Indonesia lakes throughout Indonesia is currently growing rapidly and become a mainstay of the income of fishermen around the lake. During this time water quality monitoring is done manually, which perform water quality measurement at the fish farms. In addition to requiring a long time, usually reservoirs or lakes are located far from the center of town and difficult to reach. This paper describes the design and realization of the integration of water quality monitoring systems and early warning in real time. This system has been implemented to monitor the parameters of temperature, DO (dissolved oxygen) and pH in one of the central aquaculture in Cirata. The aim of this system is to monitor water quality and prevent mass fish deaths caused by the upwelling by using an early warning system. Upwelling occurs when the value of the temperature decreases dramatically to 25 degrees and DO value decreases to $2.38 \mathrm{mg} / \mathrm{L}$. On the other hand, the data collected from measuring stations at intermediate stations can be accessed or transmitted to the master station by using a telemetry system for further analysis and study. The Results of this study show a water quality monitoring system to monitor the parameters of water quality such as temperature, DO and pH, in realtime, as well as integrated with the early warning system for upwelling phenomenon This system is built to support the cultivation of fish in lakes in Indonesia.

Keywords: early warning; fish aquaculture; real-time; temperature; upwelling; water quality.

I.

\section{Pendahuluan}

Dalam budidaya ikan menggunakan keramba jaring apung (KJA), mengetahui kualitas air yang baik sangat penting untuk menjamin kehidupan ikan sehat sepanjang periode budidaya (biasanya 3-4 bulan untuk jenis ikan mas) [1]. Meskipun banyak parameterparameter yang mempengaruhi kualitas air, tapi ada tiga yang paling penting, yaitu parameter temperatur, $\mathrm{pH}$, dan DO [2]. Fungsi pH sebagai indikator untuk reaksi kimia dan biologi dalam lingkungan air, yang digunakan sebagai ukuran keasaman atau kebasaan air. Sedangkan DO dan suhu merupakan indikator untuk metabolisme air, yang dapat digunakan untuk memantau organik serta polutan nutrisi [3], [4].

\footnotetext{
* Corresponding Author.

Email: yudiym@gmail.com

Received: April 11, 2015; Revised: April 24, 2015

Accepted: June 5, 2015

Published: June 30, 2015

(c) 2015 PPET - LIPI

doi : 10.14203/jet.v15.23-27
}

Secara konvensional, pemantauan kualitas air pada budidaya ikan dilakukan secara manual dalam mengambil sampel air, dan kemudian menganalisisnya di laboratorium [5]. Dengan teknik yang lebih maju pengukuran kualitas air dilakukan dengan menggunakan hand held instrumen secara berkala. Kedua metode ini memiliki kelemahan karena tidak praktis, tenaga kerja mahal, dan faktor kesalahan manusia yang cukup tinggi. Selain itu, cara konvensional tidak memiliki kemampuan pengumpulan data dengan baik, yang mana data tersebut sangat penting untul prediksi di masa depan dan untuk mempelajari karakteristik kualitas air di daerah budidaya [6].

Waduk yang digunakan budidaya ikan seringkali menimbulkan masalah yang cukup kompleks. Salah satunya adalah penurunan kualitas air akibat sisa pakan. Kondisi ini menjelma menjadi musibah bila terjadinya upwelling. Akibatnya, ribuan ton ikan mati seketika dan mengakibatkan kerugian yang tidak sedikit [7]. Terjadinya upwelling biasanya ditemui pada kondisi suhu air permukaan lebih dingin, dan berat jenis 
meningkat. Ketika berat jenis air di permukaan lebih besar dari air pada lapisan air lebih dalam, air permukaan akan turun mendesak air bagian dalam, dan terjadilah upwelling. Sebenarnya, yang paling merugikan pada proses upwelling di danau atau waduk ini adalah naiknya tumpukan material organik serta gas beracun [8], [9].

Untuk mengatasi masalah di atas, sistem pemantauan kualitas air secara real-time telah dirancang dan diimplementasikan di salah satu pusat budidaya ikan yang menggunakan keramba jaring apung (KJA) di Waduk Cirata. sistem ini memungkinkan tidak hanya pengumpulan data remote (jauh), tetapi juga memberikan informasi peringatan dini terjadinya upwelling secara otomatis [10].

Beberapa titik-titik stasiun pengukuran tersebut akan diintegrasikan ke stasiun perantara lalu data dari stasiun perantara dikirim ke pengendali stasiun. Keuntungan yang dimiliki tidak hanya meningkatkan pengelolaan budidaya saat ini, akan tetapi juga menyediakan data penting untuk pengembangan usaha budidaya masa depan. Desain sistem, realisasi, dan operasional akan dijelaskan di bagian berikut.

\section{SISTEM DESAIN DAN REALISASI}

Konsep dasar dari sistem monitoring secara realtime untuk budidaya ikan ditunjukkan pada Gambar 1 . Pusat untuk pengoperasian sistem ini adalah data logger yang berada di stasiun perantara, yang memiliki tiga fungsi utama. Pertama, menerima hasil pengukuran (DO, pH, dan temperatur), menampilkan hasil pengukuran, dan menyimpan data hasil pengukuran. Kedua, melakukan pengecekan ambang batas secara terus menerus untuk nilai temperatur. Terakhir, mempertahankan pengiriman data wireless ke ponsel atau stasiun pengendali. Data yang dikirim ke ponsel termasuk sinyal alarm.

Stasiun pengukuran dan stasiun perantara ditempatkan secara terapung di lokasi keramba jaring apung di sekitar Waduk Cirata dan difungsikan sebagai stasiun pengukuran kualitas air dan peringatan dini terjadinya upwelling. Sedangkan stasiun perantara memiliki fungsi sama dengan stasiun pengukuran ditambah sebagai pengumpul data hasil pengukuran dari seluruh stasiun pengukuran, mengolah data pengukuran, menampilkan datanya secara real-time dan mengirimkannya data tersebut ke stasiun pengendali. Data data ini selanjutnya juga akan tersedia secara online yang dapat diakses secara real-time dari mana saja, kapan saja dan oleh siapa saja. Modul-modul yang terlibat di setiap stasiun ditunjukkan pada Gambar 2.

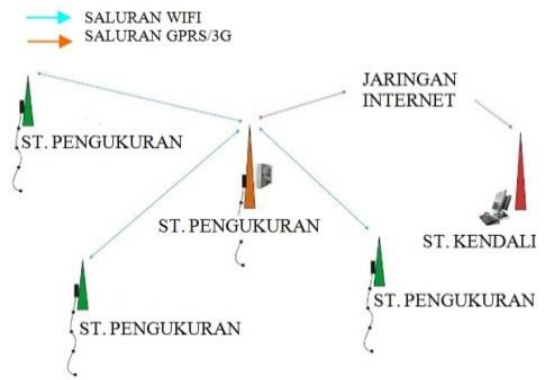

Gambar 1. Konsep Pemantauan Kualitas Air Secara Real-time dan Sistem Peringatan Dini untuk Budidaya Ikan.

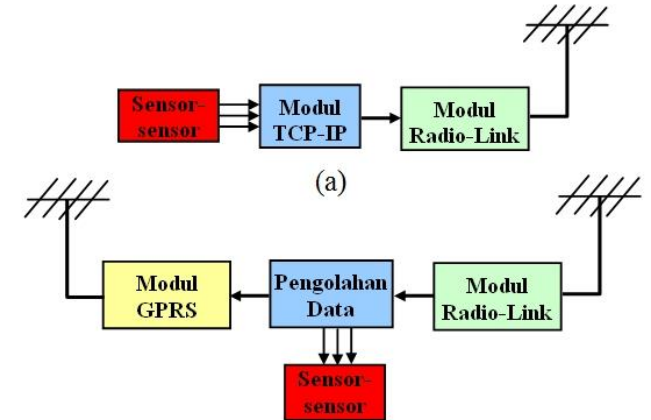

(b)

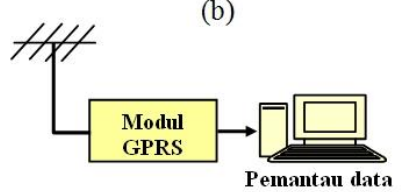

(c)

Gambar 2. Modul-modul pada, (a) Stasiun Pengukuran, (b) Stasiun Perantara, (c) Stasiun Kendali.

\section{A. Stasiun pengukuran}

Gambar 3 merupakan stasiun pengukuran yang bertugas untuk mengukur $\mathrm{pH}$, DO dan temperatur. Sensor DO, $\mathrm{pH}$, dan Temperatur yang digunakan untuk aplikasi ini adalah sensor analog yang dikemas tipe probe, di mana keluarannya dihubungkan ke sensor pemancar (Lutron TR-DOT1A4 untuk DO, TRpHT1A4 untuk pH, dan TR-TMK1A4 untuk temperatur) untuk menghindari kerugian sinyal yang disebabkan oleh panjang kabel. Dengan pemancar ini, sinyal keluaran yang dikirim oleh sensor nilainya dipertahankan pada kisaran 4-20 mA, sesuai dengan nilai DO 0-20 mg/L, nilai $\mathrm{pH} \mathrm{0-14} \mathrm{dan} \mathrm{nilai} \mathrm{temperatur}$ 0 s.d 500 derajat celsius. Data dari sensor pemancar dibaca oleh perangkat Data Acquisition Module (ADAM 6017) untuk diubah menjadi data digital secara periodik dan data tersebut masuk melalui saluran TCP/IP ke Radio Wifi client.

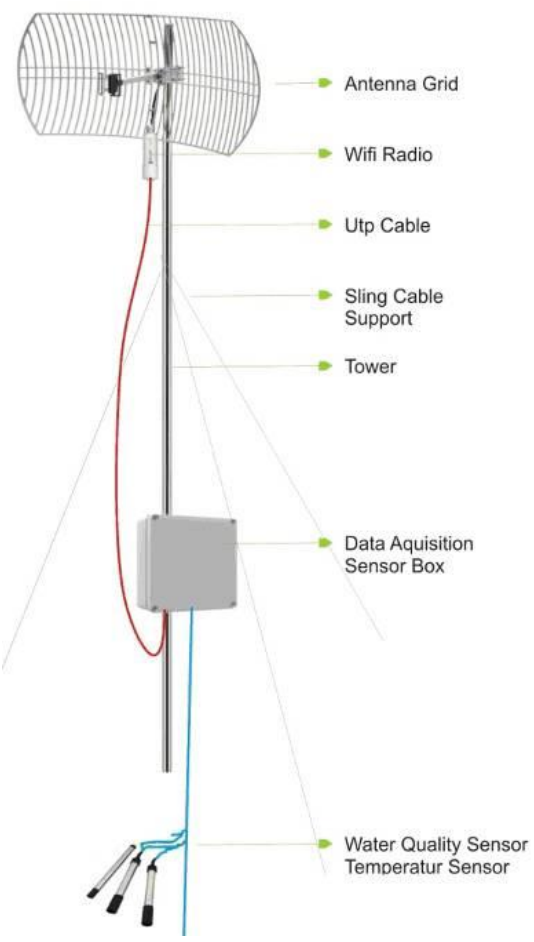

Gambar 3. Stasiun Pengukuran. 
Selanjutnya melalui Radio WiFi client yang bekerja pada frekuensi ISM 2.4GHz (Ubiquiti BULLET-2HP) inilah data dikirimkan secara nirkabel ke Stasiun Perantara dengan media transfer data digunakan jaringan WiFi berstandar $802.11 \mathrm{~g} / \mathrm{n}$ dan memiliki interval pengiriman data 1 menit. Selain itu stasiun pengukuran ini dilengkapi energi listrik tenaga surya (50 WP) sebagai sumber listriknya. Perangkat pemancar Sensor, Data Acquisition, dan Radio WiFi kemudian dimounting (agar terlindungi dari gangguan lingkungan luar). Pada Gambar 4 terlihat penempatan/pemasangan stasiun-stasiun pengukuran di KJA.

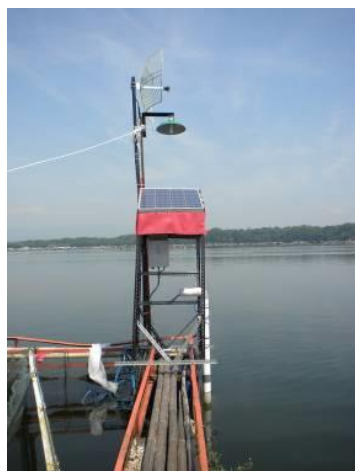

Gambar 4. Pemasangan Stasiun Pengukuran di KJA.

\section{B. Stasiun Perantara}

Gambar-5 merupakan stasiun perantara, pada prinsipnya merupakan stasiun pengukuran yang ditambahkan fungsi untuk mengumpulkan data hasil pengukuran dari stasiun lain, menampilkan hasil pengukurannya secara real-time dan kemudian mengikirimkannya ke stasiun pengendali melalui jalur koneksi internet dan jika nilai temperatur dan DO turun di bawah nilai tertentu, data logger dapat mengirim sinyal alarm ke ponsel yang ditunjuk melalui modem. Pada stasiun ini ditambahkan sebuah mini PC, modem GPRS dan GSM, LAN switch dan UPS selain itu sumber listrik menggunakan PLN.

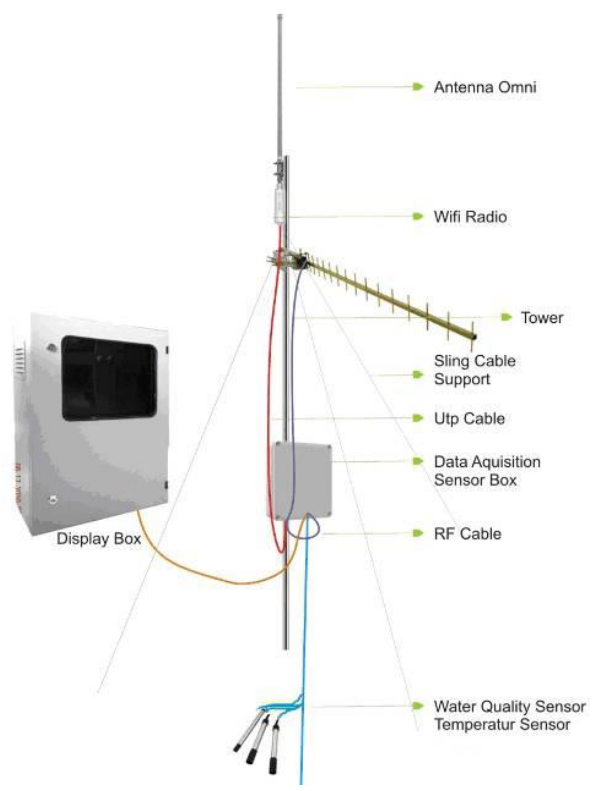

Gambar 5. Stasiun Perantara

Gambar 6 adalah kotak display monitoring yang diletakkan di dalam ruangan.

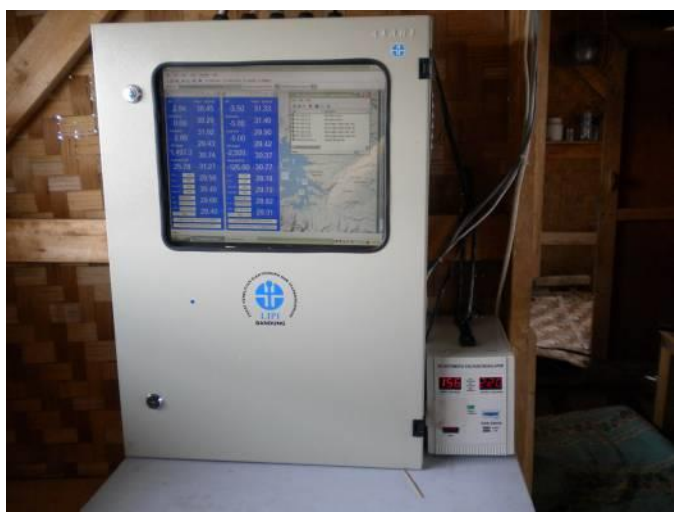

Gambar 6. Display Monitoring

\section{Software pada server di Stasiun Pengukuran}

Software pembacaan Data TCP-IP dibangun

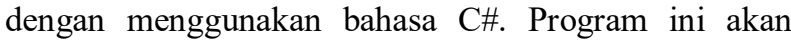
menterjemahkan output dari sensor yang berupa besaran fisis menjadi nilai-nilai yang diinginkan secara real time yang kemudian dapat dibaca pada display di layar monitor. Untuk kondisi jaringan dimonitor dengan software FREEPing, Sedangkan untuk keperluan Remote Desktop dengan bantuan LogMeIN Hamachi VPN. Berikut ini adalah tampilan stasiun perantara ketika sedang bekerja.

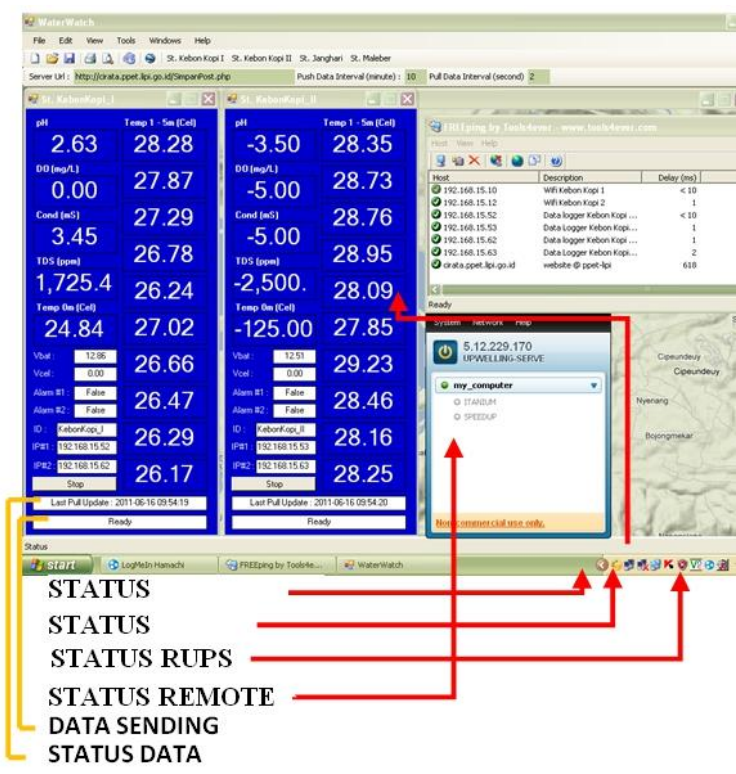

Gambar 7. Tampilan Display Monitoring di Stasiun Perantara.

Komputer SERVER secara default ketika booting akan menjalankan program:

1. LogMeInHamachi: keperluan Remote Desktop,

2. RUPS2000: keperluan Shut-Down komputer ketika listrik mati (UPS),

3. TSEL Connection: Dial-Up otomatis ke jaringan TELKOMSEL $3 \mathrm{G}$

4. FreePing: keperluan monitor jaringan di Cirata,

5. WaterWatch: Program utama sistem monitoring upwelling \& kualitas air.

Proses ini dilakukan dengan bantuan Startup Delayer Software, yang memastikan bahwa semua program akan kembali berjalan secara normal secara otomatis ketika komputer hidup kembali (startup) setelah listrik mati. 
Secara default program monitoring data (WaterWatch) ketika pertama kali dijalankan akan melakukan proses sebagai berikut:

1. Melakukan koneksi dengan stasiun pengukuran (dalam hal ini Data Acquisition modul), jika jaringan tidak tersedia atau gagal melakukan koneksi, sistem akan secara terus menerus mencoba melakukan koneksi dalam interval random setiap 1 sampai 2 menit, sampai jaringan atau koneksi tersedia.

2. Jika koneksi telah tersedia, sistem secara periodik (5 detik) akan mengambil data dari stasiun pengukukuran, dan menampilkan datanya pada layar stasiun perantara (server), dan menyimpannya pada memory sementara.

3. Setiap periode tertentu (10 menit), sistem akan mengirimkan data masing-masing stasiun pengukuran ke server upwelling, yang terdapat di LIPI, Bandung, dengan interface web. Sistem juga akan menyimpan data tersebut ke dalam file teks di dalam computer server.

4. Secara periodik (setiap hari) sistem akan melihat data data yang tidak berhasil dikirimkan ke web server ppet-lipi, yang kemungkinan disebabkan oleh adanya gangguan jaringan, dan memastikan bahwa data data tersebut dikirimkan ulang.

\section{IMPLEMENTASI TERHADAP SISTEM REAL- TIME MONITORING}

Pusat budidaya ikan yang menggunakan KJA di Indonesia berada di Jawa, Sumatera, Sulawesi dan Kalimantan. Setiap pusat memiliki karakteristik air yang berbeda serta kondisi lingkungan yang berbeda, sehingga memberikan hasil yang berbeda dari setiap musim. Walaupun dikelola oleh metodologi yang sama. Meskipun memiliki permintaan tinggi dan nilai ekonomi tinggi dari komoditas ikan di dalam negeri, pengembangan industri budidaya ikan agak lambat. Hal ini disebabkan karena kurangnya data yang memadai terkait dengan karakteristik budidaya, yang penting untuk kesuksesan masa depan dari bisnis tersebut. Gambar 8 menunjukkan lokasi stasiun pengukuran di KJA Waduk Cirata.

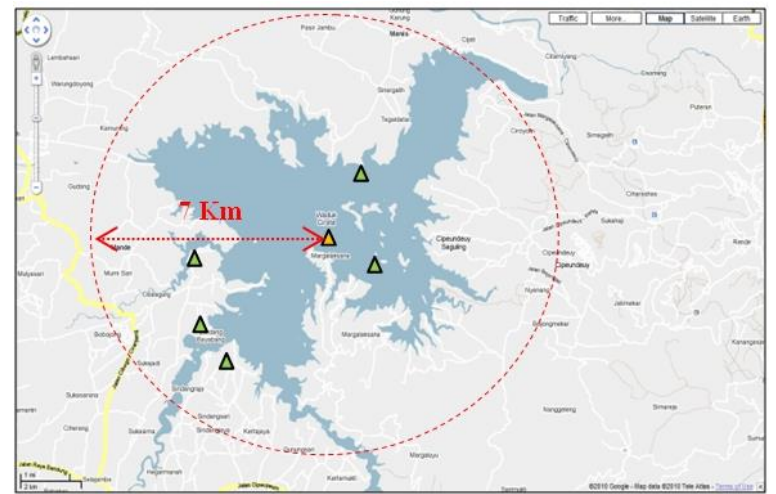

Gambar 8. Lokasi Stasiun Pengukuran Budidaya Ikan di KJA Waduk Cirata.

Stasiun pengendali akan berfungsi sebagai pusat database informasi dari semua stasiun, termasuk yang baru dikembangkan di masa depan. Gambar 9 menunjukkan struktur database software di stasiun pengendali. Setelah data disimpan, data tersebut dapat ditampilkan dengan menunjukkan nama stasiun dan tipe (dapat diintegrasikan dengan data dari stasiun kuantitas air), waktu dan tanggal pengukuran, periode (setidaknya setiap hari) analisis data, dan bentuk grafik dari data.

Dari data yang telah ditransmisikan oleh stasiun pengukuran kemudian diolah lalu ditampilkan menggunakan tabel dan bantuan google map seperti pada Gambar 9 sebagai peta digital pada lokasi di mana sensor terpasang.

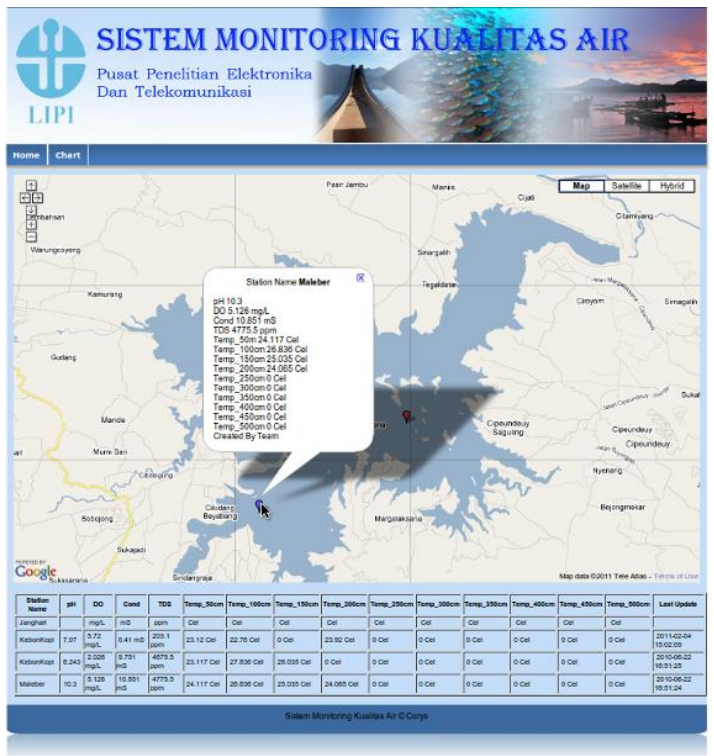

Gambar 9. Tampilan Aplikasi Sistem Monitoring Kualitas Air.

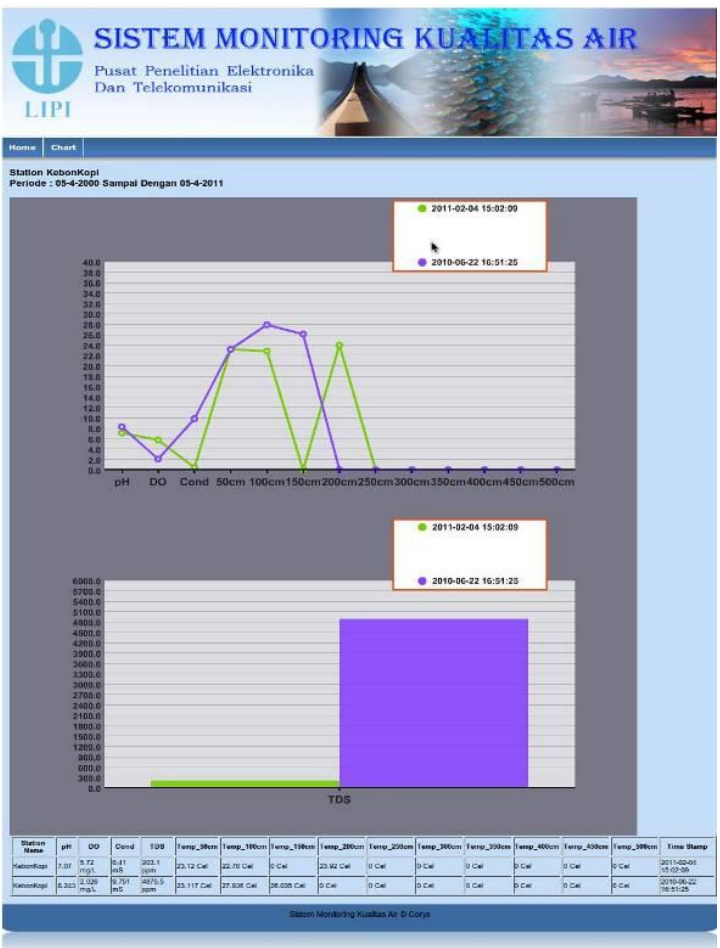

Gambar 10. Grafik Hasil Pengukuran Kualitas Air.

Dari data-data yang ada kemudian diolah menjadi bentuk grafik untuk mempermudah analisis data yang terjadi di lapangan, maka masyarakat dapat memantau kualitas air pada KJA sehingga dapat meminimalisir kerugian yang dapat ditimbulkan dari dampak upwelling. 


\section{KESIMPULAN}

Dalam tulisan ini, desain dan realisasi sistem monitoring kualitas air secara real-time terintegrasi telah dijelaskan. Sistem ini telah diterapkan untuk memantau bila terjadinya upwelling dan memonitor kualitas air di salah satu pusat budidaya ikan kramba jaring apung di waduk Cirata. Di sisi lain, data yang dikumpulkan dari pengukuran sensor di setiap budidaya dapat diakses atau dikirimkan ke stasiun pengendali dengan menggunakan sistem telemetri untuk analisis lebih lanjut. Sistem ini telah beroperasi dalam memberikan peringatan dini bila terjadi upwelling yang mengakibatkan bencana kematian ikan secara massal. Sistem yang terintegrasi saat ini sedang dikembangkan untuk memasukkan parameter baru untuk mendeteksi adanya upwelling dan akan ditingkatkan untuk pengiriman data yang lebih baik dari stasiun yang ada.

Di masa depan, diharapkan semacam sistem monitoring secara real-time dapat diterapkan di semua pusat budidaya ikan yang tersebar di Indonesia. Data kualitas air yang dikumpulkan dari masing-masing pusat budidaya kemudian dapat diintegrasikan dengan informasi lain seperti sumber daya air, bisnis, dan informasi geografis, sehingga database akan berfungsi sebagai alat pendukung pemberi keputusan untuk pengelolaan industri budidaya.

\section{UCAPAN TERIMA KASIH}

Ucapan terima kasih kami sampaikan kepada LIPI yang telah mendukung dan membiayai penelitian ini.

\section{DAFTAR PUSTAKA}

[1] L. H. Tavares, R. N. Millan, and A. A. Amaral, "Influence of management on the water quality and sediment in tropical fish farm", J. Water Res. Protec., vol. 5, pp. 495-501, May 2013.

[2] R. C. Summerfelt. (2015). Water quality considerations for aquaculture. [Online]. Available: http://southcenters.osu.edu/sites/southc/files/site-library/siteimages/WaterQualityConsiderations.pdf.

[3] R. K. Mohanty, A. Kumar, A. Mishra, D. K. Panda, D. U. Patil, Water Budgeting Management: Enhancing Aquacultural Water Productivity, Odisha, India: Directorate of Water Management, Indian Council of Agricult, (Research Bulletin, no.63), 2014.

[4] S. B. Basavaraddi, H. Kousar, and E. T. Puttaiah. "Dissolved oxygen concentration - a remarkable indicator of ground water pollution in and around Tiptur town, Tumkur District, Karnataka, India", Bull. Env., Pharm. \& Life Sci., vol. 1, iss. 3, pp. 48-54, February 2012.

[5] (2015). Monitoring water quality, volunteer stream monitoring: a methods manual. [Online]. Available: http://www.epa.gov/sites/production/files/2015-

06/documents/stream.pdf.

[6] D. S. Simbeye and S. F. Yang, "Water quality monitoring and control for aquaculture based on wireless sensor networks", $J$. Networks, vol. 9, no. 4, pp. 840-849, April 2014.

[7] E. Purbani T. (2009). Sistem monitor online cegah mati massal. [Online]. Available: http://www.agrinaonline.com/show_article.php?rid=10\&aid $=1740$.

[8] Supriyadi, B. Mulia, and H. B. Utari, "Upwelling di jatiluhur dan cirata : fenomena unik arus balik", BAIT, vol. 5, September 2013.

[9] (2008). Scientists test "artificial upwelling" to learn more about complex ocean ecosystem behavior artificial upwelling. [Online]. Available: http://oregonstate.edu/ua/ncs/archives/2008/sep/scientists-test$\%$ E2\%80\%9Cartificial-upwelling\%E2\%80\%9D-learn-moreabout-complex-ocean-ecosystem-be.

[10] Santoshkumar and V. Hiremath, "Design and development of wireless sensor network system to monitor parameters influencing fresh water fishes", Int. J. Comp. Sci. Eng., vol. 4, no. 6 , pp. 1096-1103, 2012. 